\title{
Binomial difference sequence spaces of order $m$
}

\author{
Jian Meng and Meimei Song*
}

*Correspondence: ms153106305@126.com

Department of Mathematics, Tianjin University of Technology, Tianjin, 300000, P.R. China

\begin{abstract}
In this paper, we introduce the binomial sequence spaces $b_{0}^{r, s}\left(\nabla^{(m)}\right), b_{c}^{r, s}\left(\nabla^{(m)}\right)$ and $b_{\infty}^{r, s}\left(\nabla^{(m)}\right)$ by combining the binomial transformation and $m$ th order difference operator. We prove the $B K$-property and some inclusion relations. Also, we obtain the Schauder bases and compute the $\alpha$-, $\beta$ - and $\gamma$-duals of these sequence spaces.
\end{abstract}

Keywords: sequence space; matrix domain; Schauder basis; $\alpha$-, $\beta$ - and $\gamma$-duals

\section{Introduction and preliminaries}

Let $w$ denote the space of all sequences. By $\ell_{\infty}, c$ and $c_{0}$, we denote the spaces of bounded, convergent and null sequences, respectively. We write $b s, c s$ and $\ell_{p}$ for the spaces of all bounded, convergent and $p$-absolutely summable series, respectively; $1 \leq p<\infty$. A Banach sequence space $Z$ is called a $B K$-space [1] provided each of the maps $p_{n}: Z \rightarrow \mathbb{C}$ defined by $p_{n}(x)=x_{n}$ is continuous for all $n \in \mathbb{N}$, which is of great importance in the characterization of matrix transformations between sequence spaces. It is well known that the sequence spaces $\ell_{\infty}, c$ and $c_{0}$ are $B K$-spaces with their usual sup-norm.

Let $Z$ be a sequence space, then Kizmaz [2] introduced the following difference sequence spaces:

$$
Z(\Delta)=\left\{\left(x_{k}\right) \in w:\left(\Delta x_{k}\right) \in Z\right\}
$$

for $Z \in\left\{\ell_{\infty}, c, c_{0}\right\}$, where $\Delta x_{k}=x_{k}-x_{k+1}$ for each $k \in \mathbb{N}$. Et and Colak [3] defined the generalization of the difference sequence spaces

$$
Z\left(\Delta^{m}\right)=\left\{\left(x_{k}\right) \in w:\left(\Delta^{m} x_{k}\right) \in Z\right\}
$$

for $Z \in\left\{\ell_{\infty}, c, c_{0}\right\}$, where $m \in \mathbb{N}, \Delta^{0} x_{k}=x_{k}, \Delta^{m} x_{k}=\Delta^{m-1} x_{k}-\Delta^{m-1} x_{k+1}$ for each $k \in \mathbb{N}$, which is equivalent to the binomial representation $\Delta^{m} x_{k}=\sum_{i=0}^{m}(-1)^{i}\left(\begin{array}{c}m \\ i\end{array}\right) x_{k+i}$. Since then, many authors have studied further generalization of the difference sequence spaces [4-8]. Moreover, Altay and Polat [9], Başarir [10], Başarir, Kara and Konca [11], Başarir and Kara [12-17], Başarir, Öztürk and Kara [18], Polat and Başarir [19] and many others have studied new sequence spaces from matrix point of view that represent difference operators.

For an infinite matrix $A=\left(a_{n, k}\right)$ and $x=\left(x_{k}\right) \in w$, the $A$-transform of $x$ is defined by $(A x)_{n}=\sum_{k=0}^{\infty} a_{n, k} x_{k}$ and is supposed to be convergent for all $n \in \mathbb{N}$. For two sequence

(c) The Author(s) 2017. This article is distributed under the terms of the Creative Commons Attribution 4.0 International License (http://creativecommons.org/licenses/by/4.0/), which permits unrestricted use, distribution, and reproduction in any medium, provided you give appropriate credit to the original author(s) and the source, provide a link to the Creative Commons license, and indicate if changes were made. 
spaces $X, Y$ and an infinite matrix $A=\left(a_{n, k}\right)$, the sequence space $X_{A}$ is defined by

$$
X_{A}=\left\{x=\left(x_{k}\right) \in w: A x \in X\right\},
$$

which is called the domain of matrix $A$. By $(X: Y)$, we denote the class of all matrices such that $X \subseteq Y_{A}$.

The Euler means $E^{r}$ of order $r$ is defined by the matrix $E^{r}=\left(e_{n, k}^{r}\right)$, where $0<r<1$ and

$$
e_{n, k}^{r}= \begin{cases}\left(\begin{array}{l}
n \\
k
\end{array}\right)(1-r)^{n-k} r^{k} & \text { if } 0 \leq k \leq n \\
0 & \text { if } k>n .\end{cases}
$$

The Euler sequence spaces $e_{0}^{r}, e_{c}^{r}$ and $e_{\infty}^{r}$ were defined by Altay and Başar [20] and Altay, Başar and Mursaleen [21] as follows:

$$
\begin{aligned}
& e_{0}^{r}=\left\{x=\left(x_{k}\right) \in w: \lim _{n \rightarrow \infty} \sum_{k=0}^{n}\left(\begin{array}{l}
n \\
k
\end{array}\right)(1-r)^{n-k} r^{k} x_{k}=0\right\}, \\
& e_{c}^{r}=\left\{x=\left(x_{k}\right) \in w: \lim _{n \rightarrow \infty} \sum_{k=0}^{n}\left(\begin{array}{l}
n \\
k
\end{array}\right)(1-r)^{n-k} r^{k} x_{k} \text { exists }\right\},
\end{aligned}
$$

and

$$
e_{\infty}^{r}=\left\{x=\left(x_{k}\right) \in w: \sup _{n \in \mathbb{N}}\left|\sum_{k=0}^{n}\left(\begin{array}{l}
n \\
k
\end{array}\right)(1-r)^{n-k} r^{k} x_{k}\right|<\infty\right\} .
$$

Altay and Polat [9] defined further generalization of the Euler sequence spaces $e_{0}^{r}(\nabla), e_{c}^{r}(\nabla)$ and $e_{\infty}^{r}(\nabla)$ by

$$
Z(\nabla)=\left\{x=\left(x_{k}\right) \in w:\left(\nabla x_{k}\right) \in Z\right\}
$$

for $Z \in\left\{e_{0}^{r}, e_{c}^{r}, e_{\infty}^{r}\right\}$, where $\nabla x_{k}=x_{k}-x_{k-1}$ for each $k \in \mathbb{N}$. Here any term with negative subscript is equal to naught.

Polat and Başar [19] employed the technique matrix domain of triangle limitation method for obtaining the following sequence spaces:

$$
Z\left(\nabla^{(m)}\right)=\left\{x=\left(x_{k}\right) \in w:\left(\nabla^{(m)} x_{k}\right) \in Z\right\}
$$

for $Z \in\left\{e_{0}^{r}, e_{c}^{r}, e_{\infty}^{r}\right\}$, where $\nabla^{(m)}=\left(\delta_{n, k}^{(m)}\right)$ is a triangle matrix defined by

$$
\delta_{n, k}^{(m)}= \begin{cases}(-1)^{n-k}\left(\begin{array}{c}
m \\
n-k
\end{array}\right) & \text { if } \max \{0, n-m\} \leq k \leq n, \\
0 & \text { if } 0 \leq k<\max \{0, n-m\} \text { or } k>n,\end{cases}
$$

for all $k, n, m \in \mathbb{N}$. 
Recently Bişgin $[22,23]$ defined another generalization of the Euler sequence spaces and introduced the binomial sequence spaces $b_{0}^{r, s}, b_{c}^{r, s}, b_{\infty}^{r, s}$ and $b_{p}^{r, s}$. Let $r, s \in \mathbb{R}$ and $r+s \neq 0$. Then the binomial matrix $B^{r, s}=\left(b_{n, k}^{r, s}\right)$ is defined by

$$
b_{n, k}^{r, s}= \begin{cases}\frac{1}{(s+r)^{n}}\left(\begin{array}{l}
n \\
k
\end{array}\right) s^{n-k} r^{k} & \text { if } 0 \leq k \leq n, \\
0 & \text { if } k>n,\end{cases}
$$

for all $k, n \in \mathbb{N}$. For $s r>0$ we have

(i) $\left\|B^{r, s}\right\|<\infty$,

(ii) $\lim _{n \rightarrow \infty} b_{n, k}^{r, s}=0$ for each $k \in \mathbb{N}$,

(iii) $\lim _{n \rightarrow \infty} \sum_{k} b_{n, k}^{r, s}=1$.

Thus, the binomial matrix $B^{r, s}$ is regular for $s r>0$. Unless stated otherwise, we assume that $s r>0$. If we take $s+r=1$, we obtain the Euler matrix $E^{r}$. So the binomial matrix generalizes the Euler matrix. Bişgin defined the following spaces of binomial sequences:

$$
\begin{aligned}
& b_{0}^{r, s}=\left\{x=\left(x_{k}\right) \in w: \lim _{n \rightarrow \infty} \frac{1}{(s+r)^{n}} \sum_{k=0}^{n}\left(\begin{array}{l}
n \\
k
\end{array}\right) s^{n-k} r^{k} x_{k}=0\right\}, \\
& b_{c}^{r, s}=\left\{x=\left(x_{k}\right) \in w: \lim _{n \rightarrow \infty} \frac{1}{(s+r)^{n}} \sum_{k=0}^{n}\left(\begin{array}{l}
n \\
k
\end{array}\right) s^{n-k} r^{k} x_{k} \text { exists }\right\},
\end{aligned}
$$

and

$$
b_{\infty}^{r, s}=\left\{x=\left(x_{k}\right) \in w: \sup _{n \in \mathbb{N}}\left|\frac{1}{(s+r)^{n}} \sum_{k=0}^{n}\left(\begin{array}{l}
n \\
k
\end{array}\right) s^{n-k} r^{k} x_{k}\right|<\infty\right\} .
$$

The purpose of the present paper is to study the difference spaces $b_{0}^{r, s}\left(\nabla^{(m)}\right), b_{c}^{r, s}\left(\nabla^{(m)}\right)$ and $b_{\infty}^{r, s}\left(\nabla^{(m)}\right)$ of the binomial sequence whose $B^{r, s}\left(\nabla^{(m)}\right)$-transforms are in the spaces $c_{0}$, $c$ and $\ell_{\infty}$, respectively. These new sequence spaces are the generalization of the sequence spaces defined in $[22,23]$ and [19]. Also, we give some inclusion relations and compute the bases and $\alpha$-, $\beta$ - and $\gamma$-duals of these sequence spaces.

\section{The binomial difference sequence spaces}

In this section, we introduce the spaces $b_{0}^{r, s}\left(\nabla^{(m)}\right), b_{c}^{r, s}\left(\nabla^{(m)}\right), b_{\infty}^{r, s}\left(\nabla^{(m)}\right)$ and prove the $B K$ property and inclusion relations.

We first define the binomial difference sequence spaces $b_{0}^{r, s}\left(\nabla^{(m)}\right), b_{c}^{r, s}\left(\nabla^{(m)}\right)$ and $b_{\infty}^{r, s}\left(\nabla^{(m)}\right)$ by

$$
Z\left(\nabla^{(m)}\right)=\left\{x=\left(x_{k}\right) \in w:\left(\nabla^{(m)} x_{k}\right) \in Z\right\}
$$

for $Z \in\left\{b_{0}^{r, s}, b_{c}^{r, s}, b_{\infty}^{r, s}\right\}$. By using the notion of (1.1), the sequence spaces $b_{0}^{r, s}\left(\nabla^{(m)}\right), b_{c}^{r, s}\left(\nabla^{(m)}\right)$ and $b_{\infty}^{r, s}\left(\nabla^{(m)}\right)$ can be redefined by

$$
b_{0}^{r, s}\left(\nabla^{(m)}\right)=\left(b_{0}^{r, s}\right)_{\nabla^{(m)}}, \quad b_{c}^{r, s}\left(\nabla^{(m)}\right)=\left(b_{c}^{r, s}\right)_{\nabla^{(m)}}, \quad b_{\infty}^{r, s}\left(\nabla^{(m)}\right)=\left(b_{\infty}^{r, s}\right)_{\nabla^{(m)}} .
$$

It is obvious that the sequence spaces $b_{0}^{r, s}\left(\nabla^{(m)}\right), b_{c}^{r, s}\left(\nabla^{(m)}\right)$ and $b_{\infty}^{r, s}\left(\nabla^{(m)}\right)$ may be reduced to some sequence spaces in the special cases of $s, r$ and $m \in \mathbb{N}$. For instance, we take $m=0$, 
then obtain the spaces $b_{0}^{r, s}, b_{c}^{r, s}$ and $b_{\infty}^{r, s}$ defined by Bişgin [22, 23]. On taking $s+r=1$, we obtain the spaces $e_{0}^{r}\left(\nabla^{(m)}\right), e_{c}^{r}\left(\nabla^{(m)}\right)$ and $e_{\infty}^{r}\left(\nabla^{(m)}\right)$ defined by Polat and Başar [19].

Let us define the sequence $y=\left(y_{n}\right)$ as the $B^{r, s}\left(\nabla^{(m)}\right)$-transform of a sequence $x=\left(x_{k}\right)$ by

$$
y_{n}=\left[B^{r, s}\left(\nabla^{(m)} x_{k}\right)\right]_{n}=\frac{1}{(s+r)^{n}} \sum_{k=0}^{n}\left(\begin{array}{l}
n \\
k
\end{array}\right) s^{n-k} r^{k}\left(\nabla^{(m)} x_{k}\right)
$$

for each $n \in \mathbb{N}$, where

$$
\nabla^{(m)} x_{k}=\sum_{i=0}^{m}(-1)^{i}\left(\begin{array}{c}
m \\
i
\end{array}\right) x_{k-i}=\sum_{i=\max \{0, k-m\}}^{m}(-1)^{k-i}\left(\begin{array}{c}
m \\
k-i
\end{array}\right) x_{i} .
$$

Then the binomial difference sequence spaces $b_{0}^{r, s}\left(\nabla^{(m)}\right), b_{c}^{r, s}\left(\nabla^{(m)}\right)$ and $b_{\infty}^{r, s}\left(\nabla^{(m)}\right)$ can be redefined by all sequences whose $B^{r, s}\left(\nabla^{(m)}\right)$-transforms are in the spaces $c_{0}, c$ and $\ell_{\infty}$.

Theorem 2.1 Let $Z \in\left\{b_{0}^{r, s}, b_{c}^{r, s}, b_{\infty}^{r, s}\right\}$. Then $Z\left(\nabla^{(m)}\right)$ is a BK-space with the norm $\|x\|_{Z\left(\nabla^{(m)}\right)}=$ $\left\|\left(\nabla^{(m)} x_{k}\right)\right\|_{Z}$.

Proof The sequence spaces $b_{0}^{r, s}, b_{c}^{r, s}$ and $b_{\infty}^{r, s}$ are $B K$-spaces (see [22], Theorem 2.1 and [23], Theorem 2.1). Moreover, $\nabla^{(m)}$ is a triangle matrix and (2.1) holds. By using Theorem 4.3.12 of Wilansky [24], we deduce that the binomial sequence spaces $b_{0}^{r, s}\left(\nabla^{(m)}\right), b_{c}^{r, s}\left(\nabla^{(m)}\right)$ and $b_{\infty}^{r, s}\left(\nabla^{(m)}\right)$ are $B K$-spaces.

Theorem 2.2 The sequence spaces $b_{0}^{r, s}\left(\nabla^{(m)}\right), b_{c}^{r, s}\left(\nabla^{(m)}\right)$ and $b_{\infty}^{r, s}\left(\nabla^{(m)}\right)$ are linearly isomorphic to the spaces $c_{0}, c$ and $\ell_{\infty}$, respectively.

Proof Similarly, we prove the theorem only for the space $b_{0}^{r, s}\left(\nabla^{(m)}\right)$. To prove $b_{0}^{r, s}\left(\nabla^{(m)}\right) \cong$ $c_{0}$, we must show the existence of a linear bijection between the spaces $b_{0}^{r, s}\left(\nabla^{(m)}\right)$ and $c_{0}$.

Consider $T: b_{0}^{r, s}\left(\nabla^{(m)}\right) \rightarrow c_{0}$ by $T(x)=B^{r, s}\left(\nabla^{(m)} x_{k}\right)$. The linearity of $T$ is obvious and $x=0$ whenever $T(x)=0$. Therefore, $T$ is injective.

Let $y=\left(y_{n}\right) \in c_{0}$ and define the sequence $x=\left(x_{k}\right)$ by

$$
x_{k}=\sum_{i=0}^{k}(s+r)^{i} \sum_{j=i}^{k}\left(\begin{array}{c}
m+k-j-1 \\
k-j
\end{array}\right)\left(\begin{array}{l}
j \\
i
\end{array}\right) r^{-j}(-s)^{j-i} y_{i}
$$

for each $k \in \mathbb{N}$. Then we have

$$
\lim _{n \rightarrow \infty}\left[B^{r, s}\left(\nabla^{(m)} x_{k}\right)\right]_{n}=\lim _{n \rightarrow \infty} \frac{1}{(s+r)^{n}} \sum_{k=0}^{n}\left(\begin{array}{l}
n \\
k
\end{array}\right) s^{n-k} r^{k}\left(\nabla^{(m)} x_{k}\right)=\lim _{n \rightarrow \infty} y_{n}=0,
$$

which implies that $x \in b_{0}^{r, s}\left(\nabla^{(m)}\right)$ and $T(x)=y$. Consequently, $T$ is surjective and is norm preserving. Thus, $b_{0}^{r, s}\left(\nabla^{(m)}\right) \cong c_{0}$.

The following theorems give some inclusion relations for this class of sequence spaces. We have the well-known inclusion $c_{0} \subseteq c \subseteq \ell_{\infty}$, then the corresponding extended versions also preserve this inclusion.

Theorem 2.3 The inclusion $b_{0}^{r, s}\left(\nabla^{(m)}\right) \subseteq b_{c}^{r, s}\left(\nabla^{(m)}\right) \subseteq b_{\infty}^{r, s}\left(\nabla^{(m)}\right)$ holds. 
Theorem 2.4 The inclusions $b_{0}^{r, s}\left(\nabla^{(m)}\right) \subseteq b_{0}^{r, s}\left(\nabla^{(m+1)}\right), b_{c}^{r, s}\left(\nabla^{(m)}\right) \subseteq b_{c}^{r, s}\left(\nabla^{(m+1)}\right)$ and $b_{\infty}^{r, s}\left(\nabla^{(m)}\right) \subseteq b_{\infty}^{r, s}\left(\nabla^{(m+1)}\right)$ hold.

Proof Let $x=\left(x_{k}\right) \in b_{0}^{r, s}\left(\nabla^{(m)}\right)$, then the inequality

$$
\begin{aligned}
\left|\left[B^{r, s}\left(\nabla^{(m+1)} x_{k}\right)\right]_{n}\right| & =\left|\left[B^{r, s}\left(\nabla^{(m)}\left(\nabla x_{k}\right)\right)\right]_{n}\right| \\
& =\left|\left[B^{r, s}\left(\nabla^{(m)} x_{k}\right)\right]_{n}-\left[B^{r, s}\left(\nabla^{(m)} x_{k}\right)\right]_{n-1}\right| \\
& \leq\left|\left[B^{r, s}\left(\nabla^{(m)} x_{k}\right)\right]_{n}\right|+\left|\left[B^{r, s}\left(\nabla^{(m)} x_{k}\right)\right]_{n-1}\right|
\end{aligned}
$$

holds and tends to 0 as $n \rightarrow \infty$, which implies that $x \in b_{0}^{r, s}\left(\nabla^{(m+1)}\right)$.

Theorem 2.5 The inclusions $e_{0}^{r}\left(\nabla^{(m)}\right) \subseteq b_{0}^{r, s}\left(\nabla^{(m)}\right), e_{c}^{r}\left(\nabla^{(m)}\right) \subseteq b_{c}^{r, s}\left(\nabla^{(m)}\right)$ and $e_{\infty}^{r}\left(\nabla^{(m)}\right) \subseteq$ $b_{\infty}^{r, s}\left(\nabla^{(m)}\right)$ strictly hold.

Proof Similarly, we only prove the inclusion $e_{0}^{r}\left(\nabla^{(m)}\right) \subseteq b_{0}^{r, s}\left(\nabla^{(m)}\right)$. If $r+s=1$, we have $E^{r}=$ $B^{r, s}$. So $e_{0}^{r}\left(\nabla^{(m)}\right) \subseteq b_{0}^{r, s}\left(\nabla^{(m)}\right)$ holds. Take $0<r<1$ and $s=4$. We define a sequence $x=\left(x_{k}\right)$ by

$$
x_{k}=\sum_{j=0}^{k}\left(\begin{array}{c}
m+k-j-1 \\
k-j
\end{array}\right)\left(-\frac{3}{r}\right)^{j}
$$

for all $m, k \in \mathbb{N}$. It is clear that $\left[E^{r}\left(\nabla^{(m)} x_{k}\right)\right]_{n}=\left((-2-r)^{n}\right) \notin c_{0}$ and $\left[B^{r, s}\left(\nabla^{(m)} x_{k}\right)\right]_{n}=$ $\left(\left(\frac{1}{4+r}\right)^{n}\right) \in c_{0}$. So, we have $x \in b_{0}^{r, s}\left(\nabla^{(m)}\right) \backslash e_{0}^{r}\left(\nabla^{(m)}\right)$. This shows that the inclusion $e_{0}^{r}\left(\nabla^{(m)}\right) \subseteq$ $b_{0}^{r, s}\left(\nabla^{(m)}\right)$ strictly holds.

\section{The Schauder basis and $\boldsymbol{\alpha}-, \boldsymbol{\beta}$ - and $\boldsymbol{\gamma}$-duals}

For a normed space $(X,\|\cdot\|)$, a sequence $\left\{x_{k}: x_{k} \in X\right\}_{k \in \mathbb{N}}$ is called a Schauder basis [1] if for every $x \in X$, there is an unique scalar sequence $\left(\lambda_{k}\right)$ such that $\left\|x-\sum_{k=0}^{n} \lambda_{k} x_{k}\right\| \rightarrow 0$ as $n \rightarrow \infty$. We shall construct the Schauder bases for the sequence spaces $b_{0}^{r, s}\left(\nabla^{(m)}\right)$ and $b_{c}^{r, s}\left(\nabla^{(m)}\right)$.

We define the sequence $g^{(k)}(r, s)=\left\{g_{i}^{(k)}(r, s)\right\}_{i \in \mathbb{N}}$ by

$$
g_{i}^{(k)}(r, s)= \begin{cases}0 & \text { if } 0 \leq i<k, \\
(s+r)^{k} \sum_{j=k}^{i}\left(\begin{array}{c}
m+i-j-1 \\
i-j
\end{array}\right)\left(\begin{array}{c}
j \\
k
\end{array}\right) r^{-j}(-s)^{j-k} & \text { if } i \geq k,\end{cases}
$$

for each $k \in \mathbb{N}$.

Theorem 3.1 The sequence $\left(g^{(k)}(r, s)\right)_{k \in \mathbb{N}}$ is a Schauder basis for the binomial sequence space $b_{0}^{r, s}\left(\nabla^{(m)}\right)$ and every $x=\left(x_{i}\right) \in b_{0}^{r, s}\left(\nabla^{(m)}\right)$ has an unique representation by

$$
x=\sum_{k} \lambda_{k}(r, s) g^{(k)}(r, s)
$$

where $\lambda_{k}(r, s)=\left[B^{r, s}\left(\nabla^{(m)} x_{i}\right)\right]_{k}$ for each $k \in \mathbb{N}$. 
Proof Obviously, $B^{r, s}\left(\nabla^{(m)} g_{i}^{(k)}(r, s)\right)=e_{k} \in c_{0}$, where $e_{k}$ is the sequence with 1 in the $k$ th place and zeros elsewhere for each $k \in \mathbb{N}$. This implies that $g^{(k)}(r, s) \in b_{0}^{r, s}\left(\nabla^{(m)}\right)$ for each $k \in \mathbb{N}$.

For $x \in b_{0}^{r, s}\left(\nabla^{(m)}\right)$ and $n \in \mathbb{N}$, we put

$$
x^{(n)}=\sum_{k=0}^{n} \lambda_{k}(r, s) g^{(k)}(r, s)
$$

By the linearity of $B^{r, s}\left(\nabla^{(m)}\right)$, we have

$$
B^{r, s}\left(\nabla^{(m)} x_{i}^{(n)}\right)=\sum_{k=0}^{n} \lambda_{k}(r, s) B^{r, s}\left(\nabla^{(m)} g_{i}^{(k)}(r, s)\right)=\sum_{k=0}^{n} \lambda_{k}(r, s) e_{k}
$$

and

$$
\left[B^{r, s}\left(\nabla^{(m)}\left(x_{i}-x_{i}^{(n)}\right)\right)\right]_{k}= \begin{cases}0 & \text { if } 0 \leq k<n \\ {\left[B^{r, s}\left(\nabla^{(m)} x_{i}\right)\right]_{k}} & \text { if } k \geq n\end{cases}
$$

for each $k \in \mathbb{N}$.

For every $\varepsilon>0$, there is a positive integer $n_{0}$ such that

$$
\left|\left[B^{r, s}\left(\nabla^{(m)} x_{i}\right)\right]_{k}\right|<\frac{\varepsilon}{2}
$$

for all $k \geq n_{0}$. Then we have

$$
\left\|x-x^{(n)}\right\|_{b_{0}^{r, s}\left(\nabla^{(m)}\right)}=\sup _{k \geq n}\left|\left[B^{r, s}\left(\nabla^{(m)} x_{i}\right)\right]_{k}\right| \leq \sup _{k \geq n_{0}}\left|\left[B^{r, s}\left(\nabla^{(m)} x_{i}\right)\right]_{k}\right|<\frac{\varepsilon}{2}<\varepsilon,
$$

which implies $x \in b_{0}^{r, s}\left(\nabla^{(m)}\right)$ is represented as in (3.1).

To show the uniqueness of this representation, we assume that

$$
x=\sum_{k} \mu_{k}(r, s) g^{(k)}(r, s) .
$$

Then we have

$$
\left[B^{r, s}\left(\nabla^{(m)} x_{i}\right)\right]_{k}=\sum_{k} \mu_{k}(r, s)\left[B^{r, s}\left(\nabla^{(m)} g_{i}^{(k)}(r, s)\right)\right]_{k}=\sum_{k} \mu_{k}(r, s)\left(e_{k}\right)_{k}=\mu_{k}(r, s),
$$

which is a contradiction with the assumption that $\lambda_{k}(r, s)=\left[B^{r, s}\left(\nabla^{(m)} x_{i}\right)\right]_{k}$ for each $k \in \mathbb{N}$. This shows the uniqueness of this representation.

Theorem 3.2 We define $g=\left(g_{n}\right)$ by

$$
g_{n}=\sum_{k=0}^{n}(s+r)^{k} \sum_{j=k}^{n}\left(\begin{array}{c}
m+n-j-1 \\
n-j
\end{array}\right)\left(\begin{array}{l}
j \\
k
\end{array}\right) r^{-j}(-s)^{j-k}
$$


for all $n \in \mathbb{N}$ and $\lim _{k \rightarrow \infty} \lambda_{k}(r, s)=l$. The set $\left\{g, g^{(0)}(r, s), g^{(1)}(r, s), \ldots, g^{(k)}(r, s), \ldots\right\}$ is a Schauder basis for the space $b_{c}^{r, s}\left(\nabla^{(m)}\right)$ and every $x \in b_{c}^{r, s}\left(\nabla^{(m)}\right)$ has an unique representation by

$$
x=l g+\sum_{k}\left[\lambda_{k}(r, s)-l\right] g^{(k)}(r, s) .
$$

Proof Obviously, $B^{r, s}\left(\nabla^{(m)} g_{i}^{k}(r, s)\right)=e_{k} \in c_{0} \subseteq c$ and $g \in b_{c}^{r, s}\left(\nabla^{(m)}\right)$. For $x \in b_{c}^{r, s}\left(\nabla^{(m)}\right)$, we put $y=x-\lg$ and we have $y \in b_{0}^{r, s}\left(\nabla^{(m)}\right)$. Hence, we deduce that $y$ has an unique representation by (3.1), which implies that $x$ has an unique representation by (3.2). Thus, we complete the proof.

From Theorem 2.1, we know that $b_{0}^{r, s}\left(\nabla^{(m)}\right)$ and $b_{c}^{r, s}\left(\nabla^{(m)}\right)$ are Banach spaces. By combining this fact with Theorem 3.1 and Theorem 3.2, we can give the following corollary.

Corollary 3.3 The sequence spaces $b_{0}^{r, s}\left(\nabla^{(m)}\right)$ and $b_{c}^{r, s}\left(\nabla^{(m)}\right)$ are separable.

Köthe and Toeplitz [25] first computed the dual whose elements can be represented as sequences and defined the $\alpha$-dual (or Köthe-Toeplitz dual). Chandra and Tripathy [26] generalized the notion of Köthe-Toeplitz dual of sequence spaces. Next, we compute the $\alpha$-, $\beta$ - and $\gamma$-duals of the sequence spaces $b_{0}^{r, s}\left(\nabla^{(m)}\right), b_{c}^{r, s}\left(\nabla^{(m)}\right)$ and $b_{\infty}^{r, s}\left(\nabla^{(m)}\right)$.

For the sequence spaces $X$ and $Y$, define multiplier space $M(X, Y)$ by

$$
M(X, Y)=\left\{u=\left(u_{k}\right) \in w: u x=\left(u_{k} x_{k}\right) \in Y \text { for all } x=\left(x_{k}\right) \in X\right\} .
$$

Then the $\alpha$-, $\beta$ - and $\gamma$-duals of a sequence space $X$ are defined by

$$
X^{\alpha}=M\left(X, \ell_{1}\right), \quad X^{\beta}=M(X, c s) \quad \text { and } \quad X^{\gamma}=M(X, b s),
$$

respectively.

Let us give the following properties:

$$
\begin{aligned}
& \sup _{K \in \Gamma} \sum_{n}\left|\sum_{k \in K} a_{n, k}\right|<\infty, \\
& \sup _{n \in \mathbb{N}} \sum_{k}\left|a_{n, k}\right|<\infty, \\
& \lim _{n \rightarrow \infty} a_{n, k}=a_{k} \quad \text { for each } k \in \mathbb{N}, \\
& \lim _{n \rightarrow \infty} \sum_{k} a_{n, k}=a, \\
& \lim _{n \rightarrow \infty} \sum_{k}\left|a_{n, k}\right|=\sum_{k}\left|\lim _{n \rightarrow \infty} a_{n, k}\right|,
\end{aligned}
$$

where $\Gamma$ is the collection of all finite subsets of $\mathbb{N}$.

Lemma 3.4 ([27]) Let $A=\left(a_{n, k}\right)$ be an infinite matrix, then:

(i) $A \in\left(c_{0}: \ell_{1}\right)=\left(c: \ell_{1}\right)=\left(\ell_{\infty}: \ell_{1}\right)$ if and only if (3.3) holds.

(ii) $A \in\left(c_{0}: c\right)$ if and only if (3.4) and (3.5) hold. 
(iii) $A \in(c: c)$ if and only if (3.4), (3.5) and (3.6) hold.

(iv) $A \in\left(\ell_{\infty}: c\right)$ if and only if (3.5) and (3.7) hold.

(v) $A \in\left(c_{0}: \ell_{\infty}\right)=\left(c: \ell_{\infty}\right)=\left(\ell_{\infty}: \ell_{\infty}\right)$ if and only if (3.4) holds.

Theorem 3.5 The $\alpha$-dual of the spaces $b_{0}^{r, s}\left(\nabla^{(m)}\right), b_{c}^{r, s}\left(\nabla^{(m)}\right)$ and $b_{\infty}^{r, s}\left(\nabla^{(m)}\right)$ is the set

$$
U_{1}^{r, s}=\left\{u=\left(u_{k}\right) \in w: \sup _{K \in \Gamma} \sum_{k}\left|\sum_{i \in K}(s+r)^{i} \sum_{j=i}^{k}\left(\begin{array}{c}
m+k-j-1 \\
k-j
\end{array}\right)\left(\begin{array}{c}
j \\
i
\end{array}\right) r^{-j}(-s)^{j-i} u_{k}\right|<\infty\right\} .
$$

Proof Let $u=\left(u_{k}\right) \in w$ and $x=\left(x_{k}\right)$ be defined by (2.3), then we have

$$
u_{k} x_{k}=\sum_{i=0}^{k}(s+r)^{i} \sum_{j=i}^{k}\left(\begin{array}{c}
m+k-j-1 \\
k-j
\end{array}\right)\left(\begin{array}{l}
j \\
i
\end{array}\right) r^{-j}(-s)^{j-i} u_{k} y_{i}=\left(G^{r, s} y\right)_{k}
$$

for each $k \in \mathbb{N}$, where $G^{r, s}=\left(g_{k, i}^{r, s}\right)$ is defined by

$$
g_{k, i}^{r, s}= \begin{cases}(s+r)^{i} \sum_{j=i}^{k}\left(\begin{array}{c}
m+k-j-1 \\
k-j
\end{array}\right)\left(\begin{array}{c}
j \\
i
\end{array}\right) r^{-j}(-s)^{j-i} u_{k} & \text { if } 0 \leq i \leq k, \\
0 & \text { if } i>k\end{cases}
$$

Therefore, we deduce that $u x=\left(u_{k} x_{k}\right) \in \ell_{1}$ whenever $x \in b_{0}^{r, s}\left(\nabla^{(m)}\right), b_{c}^{r, s}\left(\nabla^{(m)}\right)$ or $b_{\infty}^{r, s}\left(\nabla^{(m)}\right)$ if and only if $G^{r, s} y \in \ell_{1}$ whenever $y \in c_{0}, c$ or $\ell_{\infty}$, which implies that $u=\left(u_{k}\right) \in\left[b_{0}^{r, s}\left(\nabla^{(m)}\right)\right]^{\alpha}$, $\left[b_{c}^{r, s}\left(\nabla^{(m)}\right)\right]^{\alpha}$ or $\left[b_{\infty}^{r, s}\left(\nabla^{(m)}\right)\right]^{\alpha}$ if and only if $G^{r, s} \in\left(c_{0}: \ell_{1}\right)=\left(c: \ell_{1}\right)=\left(\ell_{\infty}: \ell_{1}\right)$. By Lemma 3.4(i), we obtain

$$
u=\left(u_{k}\right) \in\left[b_{0}^{r, s}\left(\nabla^{(m)}\right)\right]^{\alpha}=\left[b_{c}^{r, s}\left(\nabla^{(m)}\right)\right]^{\alpha}=\left[b_{\infty}^{r, s}\left(\nabla^{(m)}\right)\right]^{\alpha}
$$

if and only if

$$
\sup _{K \in \Gamma} \sum_{k}\left|\sum_{i \in K}(s+r)^{i} \sum_{j=i}^{k}\left(\begin{array}{c}
m+k-j-1 \\
k-j
\end{array}\right)\left(\begin{array}{l}
j \\
i
\end{array}\right) r^{-j}(-s)^{j-i} u_{k}\right|<\infty .
$$

Thus, we have $\left[b_{0}^{r, s}\left(\nabla^{(m)}\right)\right]^{\alpha}=\left[b_{c}^{r, s}\left(\nabla^{(m)}\right)\right]^{\alpha}=\left[b_{\infty}^{r, s}\left(\nabla^{(m)}\right)\right]^{\alpha}=U_{1}^{r, s}$.

Now, we define the sets $U_{2}^{r, s}, U_{3}^{r, s}, U_{4}^{r, s}$ and $U_{5}^{r, s}$ by

$$
\begin{aligned}
& U_{2}^{r, s}=\left\{u=\left(u_{k}\right) \in w: \sup _{n \in \mathbb{N}} \sum_{k}\left|u_{n, k}\right|<\infty\right\}, \\
& U_{3}^{r, s}=\left\{u=\left(u_{k}\right) \in w: \lim _{n \rightarrow \infty} u_{n, k} \text { exists for each } k \in \mathbb{N}\right\}, \\
& U_{4}^{r, s}=\left\{u=\left(u_{k}\right) \in w: \lim _{n \rightarrow \infty} \sum_{k}\left|u_{n, k}\right|=\sum_{k}\left|\lim _{n \rightarrow \infty} u_{n, k}\right|\right\},
\end{aligned}
$$

and

$$
U_{5}^{r, s}=\left\{u=\left(u_{k}\right) \in w: \lim _{n \rightarrow \infty} \sum_{k} u_{n, k} \text { exists }\right\},
$$


where

$$
u_{n, k}=(s+r)^{k} \sum_{i=k}^{n} \sum_{j=k}^{i}\left(\begin{array}{c}
m+i-j-1 \\
i-j
\end{array}\right)\left(\begin{array}{l}
j \\
k
\end{array}\right) r^{-j}(-s)^{j-k} u_{i}
$$

Theorem 3.6 The following equations hold:

(i) $\left[b_{0}^{r, s}\left(\nabla^{(m)}\right)\right]^{\beta}=U_{2}^{r, s} \cap U_{3}^{r, s}$,

(ii) $\left[b_{c}^{r, s}\left(\nabla^{(m)}\right)\right]^{\beta}=U_{2}^{r, s} \cap U_{3}^{r, s} \cap U_{5}^{r, s}$,

(iii) $\left[b_{\infty}^{r, s}\left(\nabla^{(m)}\right)\right]^{\beta}=U_{3}^{r, s} \cap U_{4}^{r, s}$.

Proof Since the proof may be obtained in the same way for (ii) and (iii), we only prove (i). Let $u=\left(u_{k}\right) \in w$ and $x=\left(x_{k}\right)$ be defined by (2.3), then we consider the following equation:

$$
\begin{aligned}
\sum_{k=0}^{n} u_{k} x_{k} & =\sum_{k=0}^{n} u_{k}\left[\sum_{i=0}^{k}(s+r)^{i} \sum_{j=i}^{k}\left(\begin{array}{c}
m+k-j-1 \\
k-j
\end{array}\right)\left(\begin{array}{l}
j \\
i
\end{array}\right) r^{-j}(-s)^{j-i} y_{i}\right] \\
& =\sum_{k=0}^{n}\left[(s+r)^{k} \sum_{i=k}^{n} \sum_{j=k}^{i}\left(\begin{array}{c}
m+i-j-1 \\
i-j
\end{array}\right)\left(\begin{array}{l}
j \\
k
\end{array}\right) r^{-j}(-s)^{j-k} u_{i}\right] y_{k} \\
& =\left(U^{r, s} y\right)_{n},
\end{aligned}
$$

where $U^{r, s}=\left(u_{n, k}^{r, s}\right)$ is defined by

$$
u_{n, k}= \begin{cases}(s+r)^{k} \sum_{i=k}^{n} \sum_{j=k}^{i}\left(\begin{array}{c}
m+i-j-1 \\
i-j
\end{array}\right)\left(\begin{array}{l}
j \\
k
\end{array}\right) r^{-j}(-s)^{j-k} u_{i} & \text { if } 0 \leq k \leq n \\
0 & \text { if } k>n .\end{cases}
$$

Therefore, we deduce that $u x=\left(u_{k} x_{k}\right) \in c s$ whenever $x \in b_{0}^{r, s}\left(\nabla^{(m)}\right)$ if and only if $U^{r, s} y \in c$ whenever $y \in c_{0}$, which implies that $u=\left(u_{k}\right) \in\left[b_{0}^{r, s}\left(\nabla^{(m)}\right)\right]^{\beta}$ if and only if $U^{r, s} \in\left(c_{0}: c\right)$. By Lemma 3.4(ii), we obtain $\left[b_{0}^{r, s}\left(\nabla^{(m)}\right)\right]^{\beta}=U_{2}^{r, s} \cap U_{3}^{r, s}$.

Theorem 3.7 The $\gamma$-dual of the spaces $b_{0}^{r, s}\left(\nabla^{(m)}\right), b_{c}^{r, s}\left(\nabla^{(m)}\right)$ and $b_{\infty}^{r, s}\left(\nabla^{(m)}\right)$ is the set $U_{2}^{r, s}$.

Proof Using Lemma 3.4(v) instead of (ii), the proof can be given in a similar way. So, we omit the details.

\section{Conclusion}

By considering the definitions of the binomial matrix $B^{r, s}=\left(b_{n, k}^{r, s}\right)$ and $m$ th order difference operator, we introduce the sequence spaces $b_{0}^{r, s}\left(\nabla^{(m)}\right), b_{c}^{r, s}\left(\nabla^{(m)}\right)$ and $b_{\infty}^{r, s}\left(\nabla^{(m)}\right)$. These spaces are the natural continuation of $[3,19,22,23]$. Our results are the generalization of the matrix domain of the Euler matrix of order $r$.

Acknowledgements

We wish to thank the referee for his/her constructive comments and suggestions.

Competing interests

The authors declare that they have no competing interests.

Authors' contributions

JM came up with the main ideas and drafted the manuscript. MS revised the paper. All authors read and approved the final manuscript. 


\section{Publisher's Note}

Springer Nature remains neutral with regard to jurisdictional claims in published maps and institutional affiliations.

Received: 4 May 2017 Accepted: 20 July 2017 Published online: 17 August 2017

\section{References}

1. Choudhary, B, Nanda, S: Functional Analysis with Applications. Wiley, New Delhi (1989)

2. Kizmaz, H: On certain sequence spaces. Can. Math. Bull. 24, 169-176 (1981)

3. Et, M, Colak, R: On generalized difference sequence spaces. Soochow J. Math. 21, 377-386 (1995)

4. Bektas, C, Et, M, Colak, R: Generalized difference sequence spaces and their dual spaces. J. Math. Anal. Appl. 292, 423-432 (2004)

5. Dutta, $\mathrm{H}$ : Characterization of certain matrix classes involving generalized difference summability spaces. Appl. Sci. 11, 60-67 (2009)

6. Reddy, BS: On some generalized difference sequence spaces. Soochow J. Math. 26, 377-386 (2010)

7. Tripathy, BC, Esi, A: A new type of difference sequence spaces. Int. J. Sci. Technol. 1, 147-155 (2006)

8. Tripathy, BC, Sen, M: Characterization of some matrix classes involving paranormed sequence spaces. Tamkang J. Math. 37, 155-162 (2006)

9. Altay, B, Polat, H: On some new Euler difference sequence spaces. Southeast Asian Bull. Math. 30, $209-220$ (2006)

10. Başarir, M: On the generalized Riesz B-difference sequence spaces. Filomat 24, 35-52 (2010)

11. Başarir, M, Kara, EE, Konca, S: On some new weighted Euler sequence spaces and compact operators. Math. Inequal. Appl. 17, 649-664 (2014)

12. Başarir, M, Kara, EE: On compact operators on the Riesz $B^{m}$-difference sequence spaces. Iran. J. Sci. Technol. 35 279-285 (2011)

13. Başarir, M, Kara, EE: On some difference sequence spaces of weighted means and compact operators. Ann. Funct. Anal. 2, 114-129 (2011)

14. Başarir, M, Kara, EE: On compact operators on the Riesz $B^{m}$-difference sequence spaces II. Iran. J. Sci. Technol. 33 , 371-376 (2012)

15. Başarir, $M, K a r a, E E: ~ O n$ the $B$-difference sequence space derived by generalized weighted mean and compact operators. J. Math. Anal. Appl. 391, 67-81 (2012)

16. Başarir, $M$, Kara, EE: On the $m$ th order difference sequence space of generalized weighted mean and compact operators. Acta Math. Sci. 33, 797-813 (2013)

17. Kara, EE, Başarir, M: On compact operators and some Euler $B^{(m)}$-difference sequence spaces. J. Math. Anal. Appl. 379 499-511 (2011)

18. Kara, EE, Öztürk, M, Başarir, M: Some topological and geometric properties of generalized Euler sequence space. Math. Slovaca 60, 385-398 (2010)

19. Polat, H, Başar, F: Some Euler spaces of difference sequences of order m. Acta Math. Sci. 27, 254-266 (2007)

20. Altay, B, Başar, F: On some Euler sequence spaces of nonabsolute type. Ukr. Math. J. 57, 1-17 (2005)

21. Altay, B, Başar, F, Mursaleen, M: On the Euler sequence spaces which include the spaces $\ell_{p}$ and $\ell_{\infty}$ I. Inf. Sci. 176, 1450-1462 (2006)

22. Bişgin, MC: The binomial sequence spaces of nonabsolute type. J. Inequal. Appl. 2016, 309 (2016)

23. Bişgin, $M C$ : The binomial sequence spaces which include the spaces $\ell_{p}$ and $\ell_{\infty}$ and geometric properties. J. Inequal. Appl. 2016, 304 (2016)

24. Wilansky, A: Summability through Functional Analysis. North-Holland Mathematics Studies, vol. 85. Elsevier, Amsterdam (1984)

25. Köthe, G, Toeplitz, O: Linear Raume mit unendlich vielen koordinaten and Ringe unenlicher Matrizen. J. Reine Angew. Math. 171, 193-226 (1934)

26. Chandra, P, Tripathy, BC: On generalised Köthe-Toeplitz duals of some sequence spaces. Indian J. Pure Appl. Math. 33, 1301-1306 (2002)

27. Stieglitz, M, Tietz, H: Matrixtransformationen von Folgenräumen eine Ergebnisübersicht. Math. Z. 154, 1-16 (1977)

\section{Submit your manuscript to a SpringerOpen ${ }^{\circ}$ journal and benefit from:}

- Convenient online submission

- Rigorous peer review

- Open access: articles freely available online

- High visibility within the field

- Retaining the copyright to your article

Submit your next manuscript at $\boldsymbol{s p r i n g e r o p e n . c o m ~}$ 